\title{
Model for assessing the effectiveness of rural authorities for a given financial security of the rural budget
}

\author{
Tatyana S. Lukina ${ }^{1}$, and Oleg Yu. Patlasov ${ }^{1,2, *}$ \\ ${ }^{1}$ Omsk Humanitarian Academy, 4 Cheluskintsev Street, 2a, 644105 Omsk, Russia \\ ${ }^{2}$ Smolensk state agricultural Academy, The Great Soviet, 10/2, 214000 Smolensk, Russia
}

\begin{abstract}
The consolidation of municipalities of rural settlements in the Russian Federation has been revealed due to low financial security. The budgetary expenditures in rural municipalities have been analyzed; the dependence of the budgetary expenditures insufficiency for the solution of issues of local importance and stabilization of the rural population has been revealed. A model for assessing the effectiveness of the administrating authorities of rural settlements for possible adjustments of managerial influence in overcoming crisis phenomena in rural areas and involving the population in solving issues of local importance and local development has been proposed.
\end{abstract}

\section{Introduction}

The development and formation of municipal government institutions, municipal construction in Russia seems to be an insufficiently studied phenomenon. Long-term reforms, changes in the political, economic, social systems of Russian society require a new approach to assessing the effectiveness of the activities of municipal authorities.

The decline in the number of rural municipalities and the outflow of the population from rural areas actualizes a deep analysis of the ongoing processes. In order to reverse negative trends and to retain the population in the countryside, it is necessary to assess the activities of the administrating authorities of rural areas and to promptly adjust the administrative impact; to use foreign experience of involving the population in collective activities both for solving local issues and for developing the local economy.

In parallel with public authorities, in accordance with the Constitution of the Russian Federation and Federal Law No. 131-FZ On the General Principles of Organization of Local Self-Government in the Russian Federation, there is local self-government, which means a form of solution by the population directly or through its elected bodies of their socioeconomic problems within the framework of the territory of their residence, relying mainly on their own resources, which include, first of all, their own income, the share of which is currently insignificant in the budgets of most rural settlements.

Hypothesis 1 - To identify the relationship between the directions of budgetary expenditures in rural settlements of Omsk Region on the migratory sentiments of rural

\footnotetext{
*Corresponding author: opatlasov@mail.ru
} 
residents. Are budget expenditures in the direction of "General Government Expenditures" effective?

Hypothesis 2 - The two-level system of local self-government is characterized by the blurring of the boundaries of responsibility for resolving issues of local importance.

When determining the border of a rural settlement, the principle of pedestrian connectivity to its administrative center for residents of all settlements that make up it was applied. This approach did not provide for a set of sufficient organizational-legal and financial-economic measures, which led to a decrease in the number of rural municipalities in the Russian Federation - over ten years, the number of rural settlements has decreased by 2,089 units.

The reduction in the number of municipalities has occurred as a result of the transformation (unification) and abolition; mainly these processes have affected rural settlements. Most of the rural settlements have turned out to be financially insolvent and, as a result, could not fulfill the solution of issues of local importance. The established practice of forming their budgets, when subsidies come from a higher level of budgets, not only puts municipalities in financial dependence on the regional level of government, but also forms an artificial administrative subordination of one level of local self-government to another one (municipal entity of a rural settlement - to a municipal district) [1].

According to the materials of the Ministry of Finance of the Russian Federation, in 2020, only $7.6 \%$ of the total tax revenues of municipal entities are concentrated in the budgets of rural settlements.

The distribution of own incomes by type of municipal entities as of January 1, 2021, is characterized by the following structure:

- to the budgets of urban districts $-(58.2 \%)$;

- to the budgets of municipal districts - $(30.3 \%)$;

- to the budgets of urban settlements $-(4.7 \%)$;

- to the budgets of rural settlements $-(6.8 \%)$

A decrease in income at the settlement level is related to the transfer to the budgets of municipal districts from the budgets of rural settlements of a part of the norms of receipts from the personal income tax and from the unified agricultural tax in connection with the redistribution of a number of issues of local importance from the level of rural settlements to the level of municipal districts, as well as with a decrease in the volume of grants, subsidies, and receipts from non-tax revenues, which have decreased by $35 \%$ or by 13.9 billion rubles [2].

Sources of the budget of rural settlements are tax and non-tax revenues: personal income tax (PIT), property tax (individual property tax, land tax), public due, income from the use of property, income from the sale of tangible and intangible assets, gratuitous receipts from other budgets of the budgetary system of the Russian Federation. The property tax $100 \%$ goes to the budget of the rural municipal entity. As a rule, gratuitous receipts of higher budgets for equalizing budgetary provision are also referred to the own funds of the budget, which makes it difficult to obtain reliable information about the own financial capabilities of rural municipalities. According to Omskstat data, we have analyzed the budgetary provision of rural and urban settlements that are the part of the municipal districts of Omsk Region. We considered our own funds only those that actually go to the budget of the settlement in the form of tax and non-tax revenues, excluding gratuitous receipts, which made it possible to study the real potential of the territory: in 334 out of 365 rural settlements of Omsk Region, there were not enough budgetary funds for spending on national issues, thus, $91.5 \%$ of rural municipalities needed funds from higher levels of the budget to co-finance issues for the maintenance of the administrative apparatus of rural municipalities. Expenditures on general government issues in rural settlements have the following structure: wages (over $60 \%$ ); payment for heat, water, and electricity; water disposal; communication services; the website 
maintenance, $1 \mathrm{C}$, consultant plus; fuels and lubricants, transport insurance, taxes and spare parts for transport; expenses for office supplies and household goods; repair and components for office equipment; expenses for publications in the district newspaper; Astral-Report license, etc. These costs allow organizing the maintenance of rural administrations [3].

\section{Materials and Methods}

Since 2009, in the constituent entities of the Russian Federation, the effectiveness of the activities of local self-government bodies of urban districts and municipal districts has been assessed as a part of the implementation of the Decree of the President of the Russian Federation dated April 28, 2008, No. 607 On Assessing the Effectiveness of Local SelfGovernment Bodies in Urban Districts and Municipal Districts and the Decree of the Government of the Russian Federation dated December 17, 2012, No. 1317 On Measures to Implement the Decree of the President of the Russian Federation dated April 28, 2008, No. 607 On Assessing the Effectiveness of Local Self-Government Bodies in Urban Districts and Municipal Districts and subclause "и", clause 2 of the Decree President of the Russian Federation dated May 7, 2012, No. 601 On the Main Directions of Improving the Public Administration System.

The existing system of two-level local self-government: urban district and municipal district; and rural and urban settlements have undergone many changes over a decade of practice. In 2013, the list of issues of local importance of a rural settlement, in accordance with the Charter of the municipal entity contained about 35 items. Since January 1, 2015, a part of the powers (organization within the boundaries of the settlement of electricity, heat, gas, and water supply of the population, water disposal, supply of the population with fuel; road activities; provision of low-income citizens living in the settlement and in need of accommodation, with accommodation, organization and construction of municipal housing stock; organization and construction of municipal housing stock; creation of conditions for the organization of transport services to the population; organization of collection and removal of household waste, etc.) have been transferred to the level of the district municipality. At the level of rural settlements, there are about 13 issues of local importance [4]. Analysis of the data has shown that, despite a significant reduction in issues of local importance assigned to rural authorities, the cost of maintaining rural administrations has increased.

The practice of spending in rural budgets has the following structure: national issuesmore than $65 \%$, the solution of issues on the improvement and social sphere (physical culture and sports, youth policy, culture), the remaining funds, as a rule, are less than $40 \%$.

At the present stage, many researchers suggest using criterial and indicative approaches to assessing the effectiveness of the local self-government system. In practice, the method of calculating a particular criterion (Ki) and a generalized criterion $(\mathrm{K})$ is often used. The particular criterion for assessing the effectiveness of local government bodies in the development of urban and rural settlements is determined by special evaluation indicators specified in the system of indicators for assessing the effectiveness of a particular local government body. The particular criterion for assessing the effectiveness of local government is calculated by the formula: $\mathrm{Ki}=\Phi \mathrm{i} / \Pi \mathrm{i}$

where $\mathrm{Ki}$ - the particular criterion for assessing the effectiveness of local selfgovernment;

$\Phi \mathrm{i}$ - the actually achieved value of the $\mathrm{i}^{\text {th }}$ indicator;

Mi- the planned value of the $\mathrm{i}^{\text {th }}$ indicator.

In the case when the desired result is a decrease in the value of any indicator (for example, the level of budget subsidies or the level of registered unemployment, the calculation of the private criterion is made, according to the formula): 
$\mathrm{Ki}=\Pi \mathrm{i} / \Phi \mathrm{i}$,

The final assessment of the effectiveness of local self-government bodies is carried out on the basis of the calculation of the generalized criterion $(\mathrm{K})$. The calculation is carried out, according to the formula:

$\mathrm{K}=$ sum $\mathrm{Ki} / \mathrm{i}$,

After the initial processing of information and obtaining the values of the generalized criterion $(\mathrm{K})$ for each of the assessed subjects, these values are compared with one.

When the received $\mathrm{K}$ is more than 1.1, the activity of the subject of assessment is considered to be highly effective,

at $\mathrm{K}=1+/-0.1$ - effective,

at $\mathrm{K}=0.8+/-0.1-$ low effective,

at $\mathrm{K}$ less than 0.7 , it is ineffective [5].

\section{Discussion}

Innovative assessment elements facilitate detailed examination of the economic impact on social capital in rural areas; identify different aspects, and measure social capital and governance in rural areas; use social media analysis to collect information about information sharing. E. Pisani, A. Christoforou, L. Secco, C. Burlando revealed the reputational level of power and trust between the participants. They propose a large set of indicators selected after a rigorous field test phase, field validation of methodology, and the measurement of governance in relation to social capital. Rural development is not imposed "from the outside", but also depends on endogenous factors, namely, on local cultural and environmental amenities, ecosystem services, and economic relations with urban areas that enhance rural opportunities for innovation, competitiveness, employment, and sustainable development [6].

Foreign researchers of Russian municipal policy propose the introduction of a joint discussion of the budget of a rural settlement, including technical assistance to the population of the settlement and local authorities, to introduce the practice of the public budget into the budget cycle. The training combined with local technical assistance has led to the full implementation of the public budget implementation cycle, increased citizen participation in government decision-making, and boosted local tax collection. A more significant effect was achieved when the public budget model was introduced in settlements with more years of experience in political and administrative decentralization, as a result, citizens there were more satisfied with public services [7].

The author's studies record the opposite tendencies in Russia: the involvement of the rural community in the discussion of financial documents of settlements immediately after the entry into force of the Law on Local Self-Government was an order of magnitude higher, while at present, there is a tendency of the rural population indifference when discussing not only budget issues, since a large share of the rural budget expenditures is directed to national issues, funds for solving local issues are allocated by the residual model, which in no way is a motivating factor for involving the population in the discussion of financial issues.

In the domestic scientific literature, a methodology for assessing the effectiveness of budgetary policy is being developed; the need for the State audit of budgetary policy is noted. The low efficiency of budgetary policy is associated by researchers with the lack of control and independence of government bodies that develop and implement budgetary policy [8].

Foreign research traces the changing role of the State, fiscal functions, and the importance of public spending, both in the global and national (Indian) context. Managing Government Expenditure: Searching for Lines of Control explores the historical perspective 
of government spending growth and its implications for development; analyzed the available research data and the views of various committees on the financial scenario in India, especially the financial commissions. B.S. Bhandary, G. Nagesha focused on the growth of public spending, its impact on economic growth, regional development, the quality of public spending, and the mechanisms adopted by the government to track the results of public spending [9].

The scientific paper proposes sustainable development indicators and an index suitable for monitoring and guiding development planning in villages in rural Egypt as an improvement on an existing locally calculated human development index (HDI) approach. According to the researchers, this has two main disadvantages. Firstly, economic and social inclusion (HDI) does not cover many of the important issues for rural residents. Secondly, (HDI), along with sets of international indicators for sustainable development, does not allow identifying issues that are relevant in specific national or subnational contexts. Therefore, indicators based on a simplified but holistic model of the socioeconomic and ecological system of a rural Egyptian village founded on the results of the participatory planning process were developed. A set of indicators based on a one-to-one correspondence between system components and indicators was created. This comprehensive set is detailed, but, therefore, rather cumbersome, and a core set has been selected and compared with HDI indicators for a sample of villages to demonstrate the impact of environmental and institutional considerations in setting priority areas for government intervention. The researchers concluded that the combination of a locally relevant index and an easy-tounderstand schematic approach to presenting a small set of indicators gives decision-makers an advantage over local application (HDI). A baseline was selected and compared with indicators (HDI) for a sample of villages to demonstrate the impact of considering environmental and institutional factors in setting priority areas for government intervention [10].

The experience of northern Sweden is noted with interest, when some of the villages and farmsteads became depopulated and ceased to exist; in the remaining settlements, residents began to look for ways out of the current situation. Private projects of initiative groups have turned into a movement uniting new forms of local initiative. There are currently three levels of government (planning) in Sweden: national, regional (province), and municipal (district). Having united, people have created the "fourth" level of planning based on real needs in the form of direct participation in the management of the residence territory [11]. In Sweden and Finland, the priority direction of the agrarian and social policy was the promotion of self-employment of the rural population, the development of small and medium-sized agribusiness. Support was received for rural cooperation and the integration of small and medium-sized family businesses with large national corporations operating in the service and high technology sectors.

In theory, fragmentation leads to a decrease in the cost of services per capita; decentralizes service delivery; promotes local democracy; and protects the individual and the community of interests. In An Assessment of the Impact of Local Government Fragmentation in Ghana, scholars assessed whether the prediction was consistent with the actual drivers of Ghana's fragmentation. They made the following conclusions: poverty reduction is a more important indicator of efficiency than overestimation of the government provision effectiveness; procedures and opportunities for participation are inadequate and irregular; attention is paid to the allocation of public expenditures without due regard to significant financial costs; and the consequences of fragmentation policies are ignored [12].

In the research on the mode of optimization of the spatial organization of rural settlements based on a two-way interactive mechanism between the space of rural settlements and the theory of the quality of life, it addresses three main aspects: integration of spatial function, optimization of spatial structure, and regulation of spatial scale. The 
optimization mode and the structure of the spatial organization, which is called the roadoriented mode of rural settlements, are built on the basis of the theory of the quality of life. The conceptual connotation of the regime, principles of construction, structure, type, and spatial scale are analyzed. At the same time, the work implements a reasonable proportion and optimizes the combination of the internal spatial type in settlements, and focuses on the reasonably measured scale of one settlement and the distance between settlements [13].

With regard to the up-to-date discussion among practitioners on community empowerment as a means of building local capacity to improve the quality of life, to reduce poverty, and to change at the local level, a study by M.S. Ahmad, N.B. Abu Talib illustrates an overview of the local government decentralization initiative following the announcement of Pakistan's devolution plan and assesses its participatory methods, determining how much they have improved community development at the local level. It measures the impact of community empowerment on the sustainability of community-driven projects implemented through decentralization initiatives through community-based organizations called the Citizen Community Board (CCB). The results confirm human development and improved community empowerment and sustainability of projects at the local level, a sense of community and shared benefits to be implemented in rural communities. The main goal of decentralization appears to be elusive, as only power has been transferred at the local level, resulting in less support for building community capacity, community access to resources, but still retaining an elite in the electoral process. Community development initiatives in Pakistan are said to require continued support from the local government in order to stimulate the local rural economy. Likewise, development strategies based on community and local government participation can ensure strong local ownership and empowerment among the rural community [14].

Structural analysis allows territories to analyze key variables in determining their current status and development path of the region. Municipalities face significant challenges and responsibilities towards the communities they represent; activities to strengthen participatory processes that ensure the proper use of both economic and human resources are required [15].

Quality of life and well-being is a topic of great importance for public policy and urban planning decisions. These concepts entail complex multiple socioeconomic dimensions and they are poorly defined. Quantitative assessments of the quality of life based on composite indicators have become very popular in scientific research and practice. The researchers presented an approach that integrates ideas from the adoption of multiple criteria and performance analysis to assessing the quality of life at the municipality level. A dataset involving French municipalities in 2012 was used for analysis based on a rich set of KPIs that cover various aspects of the quality of citizens' life. The relationship between the quality of life and the financial stability of municipalities has been studied [16].

\section{Results}

In the financial analysis of territories, the regulated one is especially highlighted, but the rationing of the coefficients (debt capacity ratio of the budget; municipal debt service limit ratio; coefficient of financial independence of local budgets; coefficient of coverage of the municipal budget deficit; current budgetary expenditures ratio) always poses certain disadvantages: life cycle of the territory (for example, in 2014 the city of Sevastopol became a constituent entity of the Russian Federation); remoteness from the centers of concentration of budgetary funds (Omsk District is actually a commune of residence of the city of Omsk, while Ust-Ishim is hundreds of kilometers away from the regional center); the development of the sociocultural environment (the Republic of Sakha, Tatarstan, the Chechen Republic, Jewish Autonomous Oblast, etc.) have established sociocultural features of business 
development and infrastructure projects; different natural and climatic zones (Chukotka Autonomous Okrug, Krasnodar Krai), etc. [17].

The overwhelming number of rural settlements in Omsk Region is subsidized. The deficit of own funds has been traced for a long time, including for the maintenance of the administrative apparatus of the settlements. In 2017, 67\% of municipal entities did not have their own funds to implement the costs of this area; total underfunding affects the quality of territorial management. The current situation actualizes the application of new approaches in the management of rural areas [18], including monitoring the effectiveness of the administrating of local self-government authorities of rural settlements, which can be based on the proposed model.

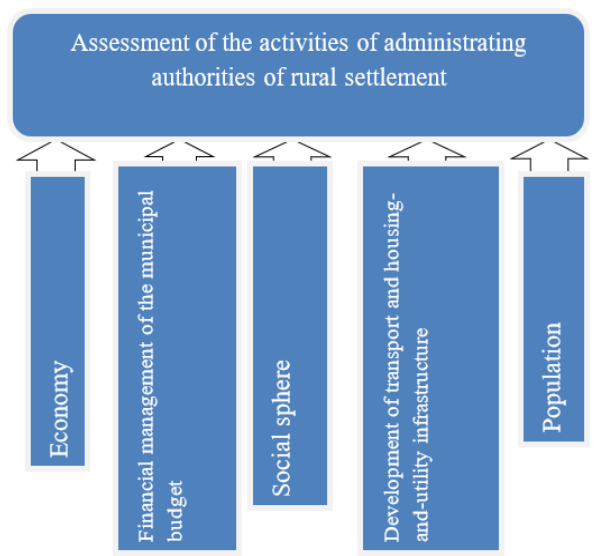

Fig. 1. A model for assessing the effectiveness of the administrating authorities of rural settlements.

We propose to select five directions for assessment (Fig. 1), to provide criteria in each direction, in accordance with the issues of local importance, enshrined in the Charter of the municipal entity. The use of this model in assessing activities over a number of years will make it possible to see which areas for a given settlement are the weakest and to adjust further management impact to reverse negative trends. The proposed model for the assessment may look like this (Table 3). The actual data are taken from Omskstat.

Table 1. Model for assessing the effectiveness of activities (On the example of Pushkin Rural Settlement of Omsk District of Omsk Region in 2018) [19].

\begin{tabular}{|l|l|l|}
\hline Indicator & PLAN & ACTUAL \\
\hline $\begin{array}{l}\text { 1. Economy: } \\
\text { 1.1 Share of the payroll of organizations of all forms of ownership of the total } \\
\text { number of labor forces living in the municipal entity, \% }\end{array}$ & 20 & 16.4 \\
\hline $\begin{array}{l}\text { 1.2 Number of organizations of all forms of ownership, operating in the territory } \\
\text { of a rural settlement, units }\end{array}$ & 200 & 168 \\
\hline 1.3 Number of catering facilities in rural areas, units & 2 & 1 \\
\hline 1.4 Number of consumer services objects in the settlement, units & 15 & 10 \\
\hline 1.5 Unemployment rate, $\%$ & 7 & 8 \\
\hline 1.6 Number of business entities that received government support & 1 \\
\hline $\begin{array}{l}\text { 1.7 Fixed capital investments } \\
\text { 1.7.1 At the expense of the municipal budget }\end{array}$ & 2 & 391 \\
1.7.2 At the expense of organizations & 400 & 500 \\
\hline $\begin{array}{l}\text { 2. Development of transport and housing-and-utility infrastructure } \\
\text { 2.1 Percentage of certified roads of the total number of public roads }\end{array}$ & 500 & 42 \\
\hline 2.2 Percentage of current road repair of the total number of roads & 45 & 42 \\
\hline $\begin{array}{l}\text { 2.3. Percentage of major repairs and reconstruction of roads of the total number } \\
\text { of roads }\end{array}$ & 1 & 6 \\
\hline 2.4. Total length of illuminated parts of streets, driveways (km) & - \\
\hline
\end{tabular}


Table 1. Continued

\begin{tabular}{|c|c|c|}
\hline $\begin{array}{l}\text { 2.5. Housing stock } \\
\text { 2.5.1. Percentage of households with permanent communications } \\
\text { 2.5.2. Water supply } \\
\text { 2.5.3. Gas supply }\end{array}$ & $\begin{array}{l}90 \\
80\end{array}$ & $\begin{array}{l}84 \\
75\end{array}$ \\
\hline 2.6. Percentage of population provision with clean drinking water & 100 & 90 \\
\hline 2.7. Provision of settlements with transport links, $\%$ & 100 & 60 \\
\hline $\begin{array}{l}\text { 2.8. The level of satisfaction with the improvement of the territory. Percentage } \\
\text { of the number of respondents (the survey is conducted by public organizations) }\end{array}$ & 95 & 52 \\
\hline 2.9. The share of the population living in ramshackle and dilapidated houses, $\%$ & 0 & 0 \\
\hline 2.10. Provision of the population with housing, with a view to sq. $\mathrm{m}$ per person & 30 & 28.3 \\
\hline $\begin{array}{l}\text { 3. Social sphere } \\
\text { 3.1. Number of cultural events held per year }\end{array}$ & 60 & 51 \\
\hline 3.2. Share of expenditures on culture of total budget expenditures, $\%$ & 4 & 1.09 \\
\hline $\begin{array}{l}\text { 3.3. Share of budget expenditures spent on the construction and reconstruction } \\
\text { of sports and children's facilities from the total budget expenditures in } \%\end{array}$ & 3 & \\
\hline $\begin{array}{l}\text { 3.4. Share of budget expenditures on physical culture and sports from total } \\
\text { budget expenditures, } \%\end{array}$ & 6 & 3.08 \\
\hline $\begin{array}{l}\text { 3.5. Number of school facilities in the settlement, units } \\
\text { 3.6. Is the population's need for educational institutions satisfied, } \% \\
\text { 3.7. Number of preschool educational institutions in the settlement, units } \\
\text { 3.8. Is the population's need for preschool institutions satisfied, } \% \\
\text { 3.9. Number of medical facilities in the settlement, units } \\
\text { 3.10. Satisfaction of the population with the availability of health care, } \%\end{array}$ & $\begin{array}{l}2 \\
2 \\
3\end{array}$ & $\begin{array}{l}2 \\
100 \\
2 \\
100 \\
2 \\
80 \\
\end{array}$ \\
\hline $\begin{array}{l}\text { 4. Financial management of the municipal budget } \\
\text { 4.1. Share of tax and non-tax revenues of the settlement's budget in the total } \\
\text { income of the settlement, } \%\end{array}$ & 60 & 67 \\
\hline $\begin{array}{l}\text { 4.2. Share of income from the use of property owned by the settlement of the } \\
\text { total tax and non-tax revenues of the settlement, } \%\end{array}$ & 10 & 5.9 \\
\hline $\begin{array}{l}\text { 4.3. Share of arrears on local taxes as of January } 1 \text { of the year following the } \\
\text { reporting year, } \%\end{array}$ & 5 & 11 \\
\hline $\begin{array}{l}\text { 4.4. Share of expenses for the maintenance of local self-government bodies of } \\
\text { the total budget of the settlement, } \%\end{array}$ & 50 & 56.5 \\
\hline $\begin{array}{l}\text { 4.5. Share of expenditures directed to the improvement of the settlement of the } \\
\text { total expenditures of the settlement, } \%\end{array}$ & 40 & 38.1 \\
\hline $\begin{array}{l}\text { 4.6. Share of the settlement budget expenditures directed to services in the } \\
\text { sphere of culture, youth policy, physical culture, and sports, \% }\end{array}$ & 10 & 4.1 \\
\hline 4.7. Budget expenditures of the rural municipality per capita (rubles) & 5,000 & 4,900 \\
\hline $\begin{array}{l}\text { 4.8. Budget expenditures for the maintenance of local self-government bodies of } \\
\text { a settlement per inhabitant (rubles) }\end{array}$ & 1,500 & 2,800 \\
\hline $\begin{array}{l}\text { 4.9. Budget expenditures of the settlement aimed at the provision of municipal } \\
\text { services in the field of culture, youth policy, physical culture, and sports, per } \\
\text { capita }\end{array}$ & 500 & 137 \\
\hline 4.10. Settlement budget expenditures aimed at landscaping per capita (rubles) & 2,900 & 1,900 \\
\hline $\begin{array}{l}\text { 5. Population } \\
\text { 5.1. Resident population of the settlement, people }\end{array}$ & 3,630 & 3,616 \\
\hline 5.2. Natural population growth & 14 & -16 \\
\hline 5.3. Positive migration balance & 10 & - \\
\hline 5.4. Number of active public organizations in the territory of a rural settlement & 5 & 2 \\
\hline 5.5. Percentage of voter turnout & 40 & 25 \\
\hline $\begin{array}{l}\text { 5.6. Satisfaction of the population with the activities of local self-government } \\
\text { bodies of the settlement, } \%\end{array}$ & 85 & 68 \\
\hline
\end{tabular}

In order to assess the effectiveness of the rural settlement administration, the $43^{\text {rd }}$ criterion has been used in five directions. The planned activities of the rural administration contribute to the actual monitoring of efficiency.

Using the formula: $\mathrm{Ki}=\Phi \mathrm{i} / \Pi \mathrm{i}$

where $\mathrm{Ki}$ - the particular criterion for assessing the effectiveness of local self-government particular criterion;

$\Phi \mathrm{i}$ - the actually achieved value of the $\mathrm{i}^{\text {th }}$ indicator; 
Пi- the planned value of the $\mathrm{i}^{\text {th }}$ indicator.

In the case when the desired result is a decrease in the value of any indicator (for example, the level of budget subsidies or the level of registered unemployment, the calculation of the private criterion is made, according to the formula):

$\mathrm{Ki}=\Pi \mathrm{i} / \Phi \mathrm{i}$,

The final assessment of the effectiveness of local self-government bodies is carried out on the basis of the calculation of the generalized criterion $(\mathrm{K})$. The calculation is carried out, according to the formula:

$\mathrm{K}=\operatorname{sum} \mathrm{Ki} / \mathrm{i}$,

According to the results of the study, it was revealed: in the sphere of economics $\mathrm{Ki}=0.78$; in the field of transport, housing and communal infrastructure, the criterion $\mathrm{Ki}=0.75$; in the social sphere $\mathrm{Ki}=0.62$; in finance, $\mathrm{Ki}=0.69$; in the population section, $\mathrm{Ki}=0.62$, according to five selected indicators of generalized criterion $\mathrm{K}-0.78+0.75+0.62+0.69+0.62 / 5=0.7$.

The generalized criterion of efficiency is 0.7 . Administration activities are ineffective. It is necessary to revise the directions of budgetary policy, including in relation to the social sphere.

The effectiveness of the activities of rural administrations and their organization of a comfortable environment for the rural population can be assessed, including by migration processes.

The total population of the districts of Omsk Region for eight years has decreased by 35,538 people, if in 2010 , there were 823,549 people in rural areas, and then in 2018 , there were 788,011 people. There are 32 rural areas in Omsk Region, and only in five rural areas, the population is increasing, but if we consider the outflow of the population in the remaining 28 rural areas, the situation looks different. The reasons for rural migration are the lack of jobs caused by the slow diversification of the rural economy, lack of prospects, and low quality of life in rural areas. If in the regional centers, the outflow of the population is less significant, then the decrease in the number of the rural population is most significant for small settlements. Forecasting the impact of migration processes on the situation in the region is possible using the cognitive modeling technique [20].

The activity of the migration flow from rural areas differs significantly by the types of villages: suburban villages and villages that are centers of municipalities (formerly the centers of village councils) are losing population more slowly than peripheral and "simple" ones in status. Proximity to the city and a higher administrative status always mean better provision of goods and services, more employment opportunities and sales of personal household products, and a higher quality of life [21]. The latter is confirmed by statistical data. Fifty-six rural settlements of Omsk Region are home to less than 500 people: six of them have less than 200 inhabitants; in twelve settlements-less than 300; up to 1000 people are in 105 rural settlements; from 1,000-1,500 inhabitants - in 85; from 1,500-2,000 people - in 53; from 2,000-3,000 - in 41 rural settlements; over 3,000 inhabitants - in 53; in general, regional centers are crowded (urban settlements in rural areas of Omsk Region, in which more than 300,000 people live) [22].

As a result, it was revealed that insufficient budget funding for solving local issues in rural settlements does not allow providing not only comfortable living in rural areas, but also does not always allow organizing uninterrupted life support (street lighting, cleaning roads from snow); as practice shows, the rural municipality fails to provide assistance in the development of agricultural production and to create conditions for the development of small and medium-sized businesses to the proper extent, which reveals the low efficiency of the activities of local authorities and predetermines migration processes. 


\section{Conclusion}

The decline in the rural population necessitates a deep assessment of the current situation in rural areas and, possibly, a review of management impact to address problematic issues and a more economical approach to budgetary expenditures. In the Russian Federation, the reduction in the number of municipalities occurs due to the unification and abolition of rural settlements. As an option, it is possible to unite rural settlements into a single district administrative okrug with the organization of local managers with the required minimum of employees in rural settlements. This approach will reduce the cost of maintaining rural administrations and will secure responsibility for the results of management activities for the regional power structure, which is currently legally assigned a wide range of powers.

The freed up budgetary funds should be directed to the development of the local economy as one of the most effective ways to develop rural areas and to keep the population in place.

Currently, there is no unified assessment of the activities of municipalities of rural settlements as the smallest structure in the system of municipal public authority. The main indicators for assessing activities should be issues of local importance defined by the Charter of the municipal entity, although practice shows that many issues assigned to one level of local self-government are closely intertwined with another one (settlement-district), for example, such as:

* creating conditions for providing residents of the settlement with communication services, catering, consumer services;

* creating conditions for organizing leisure and providing residents with cultural services;

* providing conditions for the development of physical culture and sports;

* assistance in the development of agricultural production, small and medium-sized businesses;

* implementation of activities to work with children and youth, etc.

Research on social capital in rural areas in Russia is associated with a decrease in the rural population during the migration processes of young villagers, which leads to a change in the quality of social capital in rural areas.

\section{Acknowledgements}

The paper has been prepared as a state assignment of the Ministry of Agriculture of the Russian Federation (2021) "Development of a Methodology for Using PR Technologies to Form an Attractive Image of Agricultural Education"

\section{References}

1. P.D. Kosinsky, Problems of Modern Economy, 1(53), 143 (2013)

2. Ministry of Finance of the Russian Federation. Data on the Execution of Local Budgets in the Russian Federation as of January 1 (2021) https://minfin.gov.ru

3. T.S. Lukina, XIII International Scientific and Practical Conference, 126 (2019)

4. The Charter of Pushkin rural settlement of Omsk Municipal District of Omsk Region, http://zakon.scli.ru

5. M.B. Baranov, Young Researcher, 13, 485 (2015) https://moluch.ru

6. E. Pisani, A. Christoforou, L. Secco, C. Burlando, Palgrave Macmillan, Cham (2017) https://link.springer.com

7. D.W. Beuermann, M. Amelina, Econ Gov, 19, 339 (2018) https://link.springer.com 
8. A.V. Bogoviz, A.I. Bolonin, S.V. Lobova, Springer, Cham, 622 (2018) https://link.springer.com

9. B.S. Bhandary, G. Nagesha, Public Budgeting in India. India Studies in Business and Economics. Springer (2018) https://link.springer.com

10. M.A.Khalifa, S. Connelly, Environ Dev Sustain, 11, 1175 (2009) https://link.springer.com

11. G.V. Tyurin, V.G. Tyurin, How to Raise Our Hinterland. Local Economy in Russia and in the World, 222 (2018)

12. A.K. Mohammed, Public Organiz. Rev, 16, 117 (2016)

13. X. Juan, M. Hongtu, L. Jing, Environ Sci Pollut Res, 26, 13854 (2019)

14. M.S. Ahmad, N.B. Abu Talib, Qual Quant, 49, 827 (2015)

15. V. González-Cabo, L.F. Cruz-Caicedo, M. Murgueitio, et al, Int Rev Public Nonprofit Mark, 14, 289 (2017)

16. M. Doumpos, A. Guyot, E. Galariotis, et al, Ann Oper Res, 293, 789 (2020)

17. O.Yu. Patlasov, S.N. Klimenko, Human Science: Humanities Studies, 2(32), 182 (2018)

18. T.S. Lukina, O.Yu. Patlasov, Human Science: Humanities Studies, 4(18), 225 (2014)

19. The Website of Pushkin rural settlement of Omsk Municipal District of Omsk Region, http://p-omr.ru

20. S.Kh. Mukhametdinova, O.Yu. Patlasov, R.O. Luchko, Human Science: Humanities Studies, 2(36), 174 (2019)

21. O. Yu. Patlasov, O. N. Luchko, S. Kh. Mukhametdinova, Bulletin of Siberian Federal University. Humanitarian sciences, 12(12), 2277 (2019) http://journal.sfu-kras.ru

22. Yu.G. Bychenko, V.P. Shabanov, Bulletin of Saratov State Socioeconomic University, 136

23. Federal State Statistics Service. Omskstat, http://www.gks.ru 